\title{
Vetores em contradição: planejamento da mobilidade urbana, uso do solo e dinâmicas do capitalismo contemporâneo
}

\author{
Vectors in contradiction: urban mobility planning, \\ land use and the dynamics of contemporary capitalism
}

Maurício Feijó Cruz ${ }^{[1]}$ Francisco César Pinto da Fonseca ${ }^{[l]}$

\begin{abstract}
Resumo
Este artigo analisa as relações entre as atividades de planejamento urbano no Brasil - em especial da mobilidade urbana e do uso do solo - tensionadas pelas dinâmicas do capitalismo pós-fordista, representando modelo de acumulação ao qual o planejamento governamental tende a se adaptar, embora num processo permanente de embates e contradições. Tendo em vista a Política Nacional de Mobilidade Urbana e o Estatuto da Metrópole, e à luz dos processos de espraiamento territorial dos aglomerados urbanos em escala regional, procura-se compreender perspectivas e diretrizes para que o planejamento da mobilidade urbana e metropolitana, objeto dos Planos Municipais de Mobilidade Urbana e Planos de Desenvolvimento Urbano Integrado, superem abordagens setoriais de transporte alheias à realidade advinda das dinâmicas do capital no espaço urbano.
\end{abstract}

Palavras-chave: mobilidade urbana; planejamento territorial urbano; plano municipal de mobilidade urbana; plano de desenvolvimento urbano integrado; capitalismo.

\begin{abstract}
The article analyzes the relations among urban planning activities in Brazil - especially urban mobility and land use - that are pressured by the dynamics of post-Fordist capitalism, representing an accumulation model to which governmental planning tends to adapt, although in a permanent process of clashes and contradictions. In view of the National Urban Mobility Policy and the Metropolis Statute, and in light of urban sprawl processes on a regional scale, we aim to understand perspectives and guidelines so that urban and metropolitan mobility planning, the object of both Urban Mobility Municipal Plans and Integrated Urban Development Plans, overcomes sectoral approaches to transportation that disregard the capital dynamics in the urban space.
\end{abstract}

Keywords: urban mobility; urban planning; urban mobility municipal plan; integrated urban development plan; capitalism. 


\section{Introdução}

0 objetivo deste artigo é analisar as relações entre as atividades de planejamento urbano no Brasil - em especial da mobilidade urbana e do uso do solo - contrastadas, ou tensionadas, pelas dinâmicas do chamado capitalismo pós-fordista, ou flexível, representando modelo de acumulação ao qual o planejamento governamental tende a se adaptar, embora num processo permanente de embates e contradições. Tendo em vista a lei n. 12.587/2012 (Política Nacional de Mobilidade Urbana - PNMU) e a lei n.13.089/2015 (Estatuto da Metrópole) e à luz dos processos de espraiamento territorial dos aglomerados urbanos em escala regional, procura-se compreender quais as perspectivas e as diretrizes para que o planejamento da mobilidade urbana e metropolitana, objeto dos obrigatórios Planos Municipais de Mobilidade Urbana e Planos de Desenvolvimento Urbano Integrado (PDUI), supere a elaboração de documentos setoriais de transporte alheios à realidade advinda das dinâmicas do capital no espaço urbano.

0 destaque à intrínseca ligação entre as necessidades de circulação de pessoas e os padrões de uso do solo e localização das atividades urbanas apresenta-se como perspectiva democrática para que as intervenções e os programas deles derivados promovam cidades mais equilibradas nas dimensões social, ambiental e urbanística da mobilidade. Esse maior equilíbrio é, como aludido, contrastado pelo capital internacional, uma vez que seu poder atua no sentido de assegurar-lhe condições urbanas adequadas à sua reprodução, notadamente em sua fase financeirizada, regularmente tornando obsoletos os enquadramentos tradicionais do planejamento territorial.

A hipótese apresentada é que as políticas de mobilidade urbana no Brasil, usualmente orientadas pela construção de infraestruturas (sistema viário e redes de transporte coletivo) e organização operacional para atendimento de demandas de viagem no território, carecem de análises sistematizadas e de formulação de proposições acerca dos aspectos urbanísticos e socioeconômicos dos deslocamentos, ou seja, não enfatizam a fundamental relação entre os fluxos dos habitantes e as características do meio urbano e do modo de produção da sociedade em que ocorrem. Compreendendo que a demanda por transportes é corolário do padrão de uso do solo, que a mobilidade condiciona a ocupação urbana e que 0 uso do solo é expressão da espacialização do capital - produtivo e financeiro, notadamente sua articulação -, mostra-se relevante abordar esses assuntos de maneira integrada para 0 entendimento dos processos de metropolização e diferenciação regional.

A expressão mais evidente e dramática da relação entre mobilidade, padrão de ocupação do solo e distribuição de atividades econômicas são os longos deslocamentos diários de trabalhadores de classes sociais com funções essencialmente operacionais e de baixa qualificação, orientados para periferias cada vez mais distantes dos polos de emprego, devido aos processos de valorização do solo que já atingem regiões relativamente distantes do centro. Assim, a dispersão da localização de empresas e de empreendimentos destinados aos setores de rendas altas e médias reproduz o modelo histórico de segregação do espaço urbano, expulsando sistematicamente, 
dessa forma, os mais pobres e menos qualificados para periferias cada vez mais distantes e precárias.

Entretanto, outras alterações no modelo de produção também são expressas em fenômenos espaciais diferenciados que ampliam o território urbanizado, como a multiplicação dos centros de distribuição e logística, a desconcentração industrial e a proliferação dos condomínios fechados isolados em antigas áreas rurais. Os constantes deslocamentos do capital contemporâneo subvertem, inclusive, as escalas e os recortes de planejamento tradicional, tensionando as abordagens institucionais para os fenômenos territoriais, levando à busca por novos enfoques espaciais para políticas públicas - como os conceitos de cidade metropolitana e de macrometrópole.

Dessa maneira, as políticas de mobilidade apresentam como desafio a proposição de ações que vão além da implantação de infraestruturas ou serviços de transporte, tratando, assim, da organização do espaço urbano, dos padrões de distribuição de atividades, das densidades (de empregos e residentes) e do desenho urbano. Nesse sentido, compreende-se que a sanção da Política Nacional Mobilidade Urbana institucionalizou uma transformação na abordagem da mobilidade urbana ao assumi-la como instrumento de desenvolvimento urbano e promotora de bem-estar social, assinalando o caráter do planejamento da mobilidade como política de urbanismo que, neste texto, será analisada segundo seus limites vis-à-vis os pressupostos, as características e as dinâmicas do capitalismo contemporâneo.

Por fim, cabe ressaltar que a análise aqui empreendida busca analisar tais dinâmicas urbanas em uma perspectiva estrutural, como "vetores", e não por meio de estudos de casos específicos.

\section{Lógica e dinâmica do capitalismo contemporâneo nas metrópoles: pós-fordismo e flexibilização}

Sem a pretensão de esgotar toda a complexidade do modelo de acumulação capitalista vigente desde a década de 1970 até os dias de hoje, apresenta-se abaixo panorama das características marcantes da lógica e da dinâmica do capitalismo contemporâneo, cujos impactos são brutais para o uso e ocupação do solo. As de ideias-chave, personificadas em propostas e programas de governo, desenvolvidas pelos intelectuais ultraliberais, ${ }^{1}$ pode ser assim caracterizadas:

- precedência da esfera privada (o indivíduo livre no mercado) sobre a esfera pública;

- desestatização da economia, privatizando-se todas as empresas sob controle do Estado;

- desproteção dos capitais nacionais, que deveriam competir livremente com seus congêneres estrangeiros;

- desestruturação do Estado de bem-estar social, pois concebido e estigmatizado como ineficaz, ineficiente, perdulário, injusto/autoritário (por transferir aos mais pobres parcelas de renda dos mais ricos ou bem-sucedidos, que assim o seriam, por seus próprios méritos) e indutor de comportamentos não valorizadores do mérito e do esforço pessoais;

- pressão política e econômica pela quebra do pacto corporativo entre capital e trabalho, 
em nome da liberdade de escolha individual e da soberania do consumidor;

- desregulação e desregulamentação da produção, da circulação dos bens e serviços, do mercado financeiro, das relações de trabalho e de todas as formas de mercado, entre as quais o imobiliário;

- ênfase nas virtudes do livre-mercado, como instrumento prodigioso por aumentar a riqueza, gerando em consequência uma "natural" distribuição de renda, em razão do aumento da produtividade, e como único mecanismo possível de refletir os preços reais dos produtos e serviços, possibilitando, aos indivíduos, o exercício de cálculos em relação à atividade econômica;

- concepção de liberdade como "liberdade de mercado", isto é, ausência de empecilhos à relação capital/trabalho e ao livre desenvolvimento dos fatores produtivos;

- concepção "negativa" da liberdade, isto é, caracterizada como ausência de interferências, que não apenas as consideradas imprescindíveis à vida em sociedade;

- o somente se possibilitadora do mercado livre e da liberdade individual;

- concepção de que a sociedade deve oferecer a cada indivíduo (no aspecto fiscal e quanto a eventuais equipamentos públicos) apenas e tão somente o quanto este contribuíra para a mesma, devendo refletir méritos distintos, valorizando-se, assim, a desigualdade;

- suprema valorização do sistema jurídico (nomocracia), pois estruturante e avalista de sociedades (contratuais) compostas por indivíduos autônomos em suas ações em razão de seus interesses;

- crença de que o Estado interventor é, intrinsecamente, produtor de inúmeras crises: fiscal, burocrática, de produtividade, entre outras, o que origina demandas pelas "reformas do Estado orientadas para o mercado" e pela diminuição de impostos e dos gastos governamentais;

- ênfase nas mínimas, porém importantes, funções do Estado: garantia da ordem e da paz, da propriedade privada e dos contratos "livremente" elaborados entre os indivíduos; proteção do (suposto) "livre mercado", por meio da proibição de práticas anti-concorrenciais e da elaboração de "normas gerais e abstratas"; desregulamentação, desregulação e flexibilização de todos os mercados: de capitais, financeiro, produtivo e de trabalho.

Como se observa, o receituário ultraliberal - expressão do pós-fordismo e consequentemente da fase financeirizada, rentista, do capital -, adaptado ao longo do tempo às circunstâncias e resistências, mas fortemente atuante nas correlações de força em todos os setores, afeta profundamente o uso e a ocupação do solo: os grandes empreendimentos industriais e comerciais; os condomínios voltados às classes médias superiores e às elites; as zonas de tráfego estratégicas aos fluxos econômicos; as pressões do capital - em suas diversas frações por alterações nos Planos Diretores municipais com impactos diretos nos bairros, nas cidades e nas regiões; a delimitação do uso e da ocupação do solo nas zonas urbanas - e claramente nas zonas rurais dependendo do setor econômico majoritário - de acordo com a cadeia produtiva; entre inúmeros outros impactos que são observados produzindo brutal desigualdade social no território. A enorme dificuldade em universalizar a rede de esgoto - coleta e tratamento - deve-se, entre inúmeros outros fatores, à corrida inglória do poder público por 
um ambiente urbano equilibrado que, dessa forma, permanece estrutural e dinamicamente excludente: daí a "periferização" ser um movimento interminável, articulando municípios vizinhos pela pobreza e vulnerabilidade em meio à opulência das cadeias "produtivas".

As características acima arroladas do modelo ultraliberal estão se transformando, segundo Dardot e Laval (2016), numa "nova razão do mundo", no sentido de balizarem o papel do Estado, o espaço público sobreposto pelo privado, a lógica empresarial acima de todos os valores e a própria subjetividade dos indivíduos tomada pela perspectiva do "capital humano", em que tudo é suposta concorrência, meritocracia e individualismo mercantilizado. Segundo os autores, haveria

[...] uma subordinação a certo tipo de racionalidade política e social articulada à globalização e à financeirização do capitalismo. Em uma palavra, só há "grande virada" [da social democracia ao neoliberalismo] mediante a implantação geral de uma nova lógica normativa, capaz de incorporar e reorientar duradouramente políticas e comportamentos numa nova direção. (Ibid., p. 190)

Portanto, essa nova lógica se insere nas estruturas do Estado Nacional, das empresas, dos indivíduos (notadamente dos trabalhadores) e da vida em sociedade no sentido de balizar o sentido de eficiência, eficácia, produtividade, sempre na lógica da mercantilização e de todos os fatores, entre os quais os seres humanos, em uma perspectiva muito mais holística do que a vigente até então.

Especificamente quanto ao uso e ocupação do solo, a lógica imobiliária vinculada tanto ao capital produtivo quanto ao especulativo - fortemente articulados pelo capitalismo contemporâneo - impõe uma série de dinâmicas urbanas: a privatização do espaço por meio de condomínios voltados às classes médias, assim como seu oposto, a circunscrição dos pobres em lugares distantes e degradados; a criação de novos espaços comerciais em áreas antes destinadas a moradias; a destruição e reconstrução de bairros e áreas por interesses essencialmente mercantis e sem qualquer processo de consulta; entre tantos outros processos. A naturalização do papel dos "investidores" quanto ao uso e à ocupação do solo é expressão do poder do capital, uma vez que áreas de interesse social, comunitário e coletivo são fortemente substituídas pela privatização do público e pela imposição daquele sobre este.

0 Estatuto da Cidade, os Planos Diretores e outros instrumentos legais são importantes ferramentas - como veremos abaixo - de resistência, de tentativa de equilíbrio e de indução, mas seus limites parecem evidentes, como se observa nas metrópoles brasileiras. Tais processos não são obviamente coincidências, e sim fazem parte do modus operandi ultraliberal no ambiente urbano, uma vez que o uso e a ocupação do solo determinam vigorosamente os padrões de fluxo de pessoas, mercadorias e, consequentemente, dos veículos (em sistemas públicos ou privados) utilizados. Portanto, a mobilidade nos espaços urbanos é consequência das tomadas de decisão dos empreendimentos econômicos, por si só autóctones, notadamente em países como o Brasil, cujas instituições historicamente não foram capazes de delimitar estritamente o comportamento dos agentes econômicos mais poderosos. É claro que, em contraste a esse vetor do capital, é possível (ou não, dependendo de qual grupo político esteja 
no comando) ao Estado erigir barreiras e anteparos que diminuam os impactos negativos e, sobretudo, criar legislação - caso dos estatutos e leis abordados neste artigo - e instituições capazes de induzir os comportamentos desses agentes, impedindo a completa liberdade de imposição do privado sobre o público. Trata-se fundamentalmente de relação dialética entre esses dois vetores.

Por fim, há de se ressaltar que há importantes mudanças no modelo de produção com impactos diretos e indiretos no ambiente urbano e regional, em diversas dimensões. Especificamente quanto à reestruturação produtiva, paulatinamente tornada flexível, observam-se importantes alterações nos seguintes aspectos:

- introdução de novas tecnologias (informática, robótica e outras) e de novos modelos de gestão empresarial (reengenharia, downsizing, just in time, entre outras) na atividade produtiva, que implicam, via de regra, a redução do trabalho socialmente necessário ao capital;

- utilização do incessante processo de subcontratação - terceirização e quarteirização - de empresas de tamanho, tecnologia e qualificação díspares em substituição à clássica "empresa gigante" fordista;

- expansão geográfica da produção econômica, isto é, arrefecimento das fronteiras nacionais em termos de produção/circulação de produtos e serviços;

- rompimento do pacto entre capital e trabalho, até então intermediado pelo Estado, implicando brutal diminuição do poder dos sindicatos, de modo que a relação capital/trabalho se torna claramente pendente para o primeiro, mesmo levando-se em consideração as transformações na propriedade das empresas;
- enfraquecimento da força de trabalho devido à flexibilização da proteção à mão de obra e à internacionalização dos processos produtivos, fragilizando-a ainda mais;

- organização da produção pelas grandes corporações intituladas "transnacionais", em escala mundial, cujas tomadas de decisão encontram-se nos países do G-7;

- a revolução tecnológica, condutora da terceira revolução industrial, que destitui classes sociais - e consequentemente seus valores e territórios onde se instauraram originalmente -, abrindo espaço para outras formas de produção e circulação de bens tangíveis e intangíveis;

- a ordem internacional, a partir da grandes potências e com a presença crescente da China, que vem suplantando instituições multilaterais criadas no pós-segunda guerra mundial, colocando em xeque o poder das instituições e reforçando o poder do capital privado a partir do G-7, com efeitos ainda mais drásticos nos países periféricos (por mais que esse conceito também esteja passando por transformações) que são somente receptores de decisões tomadas e, portanto, sem poder de decisão sobre atividades e empreendimentos econômicos em seu próprio país.

Segundo Harvey (2004, p. 140):

A acumulação flexível [...] é marcada por um confronto direto com a rigidez do fordismo. Ela se apoia na flexibilidade dos processos de trabalho, dos mercados de trabalho, dos produtos e padrões de consumo. Caracteriza-se pelo surgimento de setores de produção inteiramente novos, novas maneiras de fornecimento de serviços financeiros, novos mercados e, sobretudo, taxas altamente intensificadas de inovação comercial, tecnológica 
e organizacional. A acumulação flexível envolve rápidas mudanças dos padrões do desenvolvimento desigual, tanto entre setores como entre regiões geográficas, criando, por exemplo, um vasto movimento no emprego no chamado "setor de serviços" [...].

Como se observa, a lógica da flexibilização de todos os fatores produtivos é crucial ao modelo de acumulação contemporâneo, não apenas por superar o fordismo, mas sobretudo por intensificar economia de custos (notadamente do trabalho), rapidez da circulação e maximização dos lucros.

Dessa forma, o uso e a ocupação do solo e a mobilidade que deles decorre advêm, notadamente na contemporaneidade, de capitais cuja origem provém do capitalismo central. Às instituições e legislações nacionais, em especial de países como o Brasil, aparentemente tem competido papel mais voltado à adaptação a tal cenário internacional do que propriamente autonomia e empoderamento capazes de impor e delimitar a presença de capitais que, por seu turno, consideram o uso e a ocupação do solo e a facilidade de seus fluxos cruciais aos seus empreendimentos.

Veremos, a seguir, o papel das legislações criadas no Brasil recentemente como forma de regrar o uso e ocupação do solo e o problema da mobilidade. Dessa forma, será possível cotejar planejamento urbano e dinâmica do capitalismo contemporâneo.

\section{A Política Nacional de Mobilidade Urbana}

Após longo processo político de formulação e discussão do projeto de lei de diretrizes da
Política de Mobilidade Urbana (projeto de lei n. 1.687/2007), foi instituída, em janeiro de 2012, a Política Nacional de Mobilidade Urbana (PNMU) por meio da lei 12.587, na qual foi sistematizado um conjunto de fundamentos, princípios, objetivos, direitos e instrumentos relativos ao planejamento dos deslocamentos dos cidadãos nas cidades brasileiras (Gomide, 2008). Essa Lei indica os parâmetros para a formulação e execução de uma política nacional de mobilidade urbana em um contexto de Estado democrático - no qual as decisões sobre as ações públicas passam necessariamente por processos amplos de participação popular - e baseado em cooperação federativa, compreendendo a mobilidade como um instrumento de desenvolvimento urbano e de promoção do bem-estar social.

Entre os princípios da Lei, destacam-se aspectos técnicos (segurança nos deslocamentos, priorização de formas não motorizadas de deslocamento, foco no transporte coletivo, intermodalidade, uso de fontes de energia renováveis, hierarquização de redes, desenvolvimento sustentável) e sociais (acessibilidade universal, equidade no acesso ao transporte coletivo, transparência e participação no planejamento, controle e avaliação da política, justa distribuição dos benefícios e ônus decorrentes do uso dos diferentes meios e serviços). Nesse sentido, a Política Nacional de Mobilidade Urbana segue preceitos estabelecidos pelo Estatuto da Cidade (lei 10.257, de 10 de julho de 2001) relativos à participação popular na definição das políticas urbanas, à função social da cidade e à conjugação de instrumentos urbanísticos para a promoção do desenvolvimento urbano, redução de desigualdades sociais, 
qualificação da vida urbana e planejamento do crescimento das cidades.

A lei 12.587 previu, assim, a constituição de uma política de mobilidade mais abrangente do que os planos de transportes focavam historicamente, cujos escopos se concentravam nos serviços de transporte urbano e na implantação de infraestrutura. ${ }^{2}$ Para superar a visão de que a mobilidade urbana trata apenas do conjunto de serviços e infraestruturas para circulação da população, a Lei destaca a relação dos deslocamentos das pessoas e bens com o meio urbano, indicando a necessária integração da política de mobilidade com a de controle e uso do solo. Assim, a PNMU institucionaliza a política de mobilidade como política de urbanismo, relacionando-a à organização (regulação, controle e planejamento) do espaço urbano.

Para promover políticas locais relativas à mobilidade, a PNMU apresenta instrumentos de gestão disponíveis para os municípios, como restrição e controle de acesso e circulação de veículos motorizados em locais e horários predeterminados (inclusive o uso prioritário ou exclusivo de vias para o transporte coletivo), estipulação de padrões de emissão de poluentes e aplicação de tributos específicos visando a desestimular ou a incentivar o uso de determinados modos e serviços de mobilidade, entre outros. Entretanto, a lei 12.587 indica que 0 instrumento fundamental para a implantação da Política de Mobilidade Urbana é o Plano de Mobilidade Urbana (PMU), exigido para municípios com mais de 20 mil habitantes e em todos os demais obrigados, pelo Estatuto da Cidade, à elaboração de Plano Diretor. A Lei estipulava que aqueles que não o fizessem no prazo máximo de 3 anos da vigência da Lei - portanto até abril de 2015 - estariam impedidos de receber verbas federais destinadas à mobilidade urbana. Ainda que não tenham existido sanções aos municípios que não concluíram seus Planos de Mobilidade até 0 momento, ${ }^{3}$ diversos deles iniciaram a preparação de seus Planos de Mobilidade à luz da PNMU, e já existem exemplos de como os governos locais trataram da conjugação do planejamento dos deslocamentos da população no território com as questões de uso do solo e desenvolvimento urbano por meio do entendimento de que a demanda por transportes é consequência do padrão de uso do solo e que a ocupação urbana é condicionada pela mobilidade.

Como se observa, trata-se de lei com claro espírito democrático no sentido de a cidade ser voltada aos cidadãos, que dela deveriam se apropriar para abordar o planejamento da mobilidade, assumindo-o como instrumento de desenvolvimento urbano e promotor de bem-estar social. Contudo, o poder do grande capital escapa, em larga medida, aos ditames e intuitos normatizadores e indutores da lei, exercendo seu poder de definição socioespacial de atividades econômicas que reestruturam o território e criam dinâmicas de ocupações e fluxos que, de certa forma, balizam as próprias legislações. Isso ocorre, especialmente, por meio das atividades imobiliárias que forçam tanto a expansão da mancha urbana quanto sua necessária estruturação para atendimento de novos loteamentos, conjuntos residenciais (como os vários casos de empreendimentos do Programa Minha Casa Minha Vida implantados em novas periferias desconectadas do tecido urbano existente) ou áreas eleitas pelo mercado para abrigar novas centralidades. 
As pressões do capital influenciam a priorização de ações previstas (ou não) nos planos, enfatizando grandes obras que canalizam recursos para empreiteiras, criação de parcerias público-privadas para implantação de infraestruturas que geram novos negócios para fundos de investimento ou a manutenção da concessão de serviços de transporte por ônibus que fortalecem grupos empresariais de operadores. Da mesma forma, o modelo produtivo impõe vetos às iniciativas de fomento aos transportes ativos, tanto para deslocamentos a pé quanto por bicicleta, ${ }^{4}$ que possam vir a reduzir o espaço viário destinado aos automóveis ou que ameacem seu protagonismo na organização da circulação urbana - o que também inclui a recorrente omissão quanto a uma real qualificação dos sistemas de transporte coletivo. Assim, os paradigmas de mobilidade urbana dificilmente são alterados pelos planos elaborados, constituindo-se em sua maioria tentativas modestas de adequação mínima dos serviços de transporte e reprodução dos modelos vigentes de organização da circulação na cidade.

Segundo Offe (1984), existiriam quatro condicionantes estabelecidos pelo modelo de acumulação capitalista à atuação do Estado:

a) A privatização da produção: o poder público está estruturalmente impedido de organizar a produção material segundo seus próprios critérios políticos. [...] b) A dependência dos impostos: o poder público depende, indiretamente, através de mecanismos do sistema tributário, do volume da acumulação privada. [...] c) $A$ acumulação como ponto de referência: como o poder estatal depende do processo de acumulação capitalista, sem ser ele mesmo capaz de organizar este processo, o interesse supremo e mais geral dos detentores do poder do Estado consiste em manter as condições de exteriorização de seu poder através da constituição de condições políticas que favoreçam o processo privado de acumulação. [...] d) A legitimação democrática: [...] 0 exercício do poder através dos mecanismos democrático-representativos da formação das vontades e da regulamentação dos conflitos tem o sentido, no contexto do Estado constitucional burguês, de assegurar de forma politicamente duradoura - e não somente através de preceitos constitucionais - a delimitação da esfera privada e da esfera de liberdade econômica, de forma a defender essa esfera de liberdade de possíveis intrusões por parte do Estado. [...] Em outras palavras: o Estado capitalista está sujeito a uma dupla determinação do poder político - segundo sua forma institucional, este poder é determinado pelas regras do governo democrático-representativo; segundo o seu conteúdo, é determinado pelo desenvolvimento e pelos requisitos do processo de acumulação. (pp. 124-125; grifos do autor)

Como se observa, o Estado está estruturalmente limitado pelo capitalismo - daí os condicionantes -, embora tais limitações sejam fundamentalmente objeto de disputas, conflitos, vetos e proposições pelos mais diversos grupos sociais, entre os quais os detentores do capital. A chamada "guerra fiscal" aplicada por municípios e estados brasileiros nada mais é do que a adaptação a esses condicionantes.

A disputa política em torno do conteúdo dos planos de uso e ocupação do solo, da mobilidade urbana, dos estatutos que regem as cidades, entre outros códigos nacionais e internacionais, expressam as resistências, mas também o diálogo, entre o poder público e os 
empreendimentos econômicos, cada vez mais transnacionalizados, o que é um problema adicional à dinâmica do território.

\section{Investimentos recentes em infraestrutura e as manifestações de 2013}

Concomitante ao quadro de elaboração de planos municipais, os ciclos de investimentos em infraestrutura representados pelos Programas de Aceleração do Crescimento (PAC) desde 2007 incluíram diversos projetos de mobilidade urbana que financiaram obras para circulação nas cidades brasileiras, especialmente nas cidades-sede da Copa do Mundo Fifa de 2014. No Eixo Infraestrutura Social e Urbana, o item Mobilidade Urbana, em 2016, somava R\$15,4 bilhões, alocados para intervenções em 19 empreendimentos já concluídos ou em operação, R\$ 68,6 bilhões em 110 obras em andamento, além de 7 projetos em licitação de obra e 185 em fase de ação preparatória, envolvendo 107 municípios com empreendimentos de corredores de ônibus, sistemas BRT (Bus Rapid Transit), linhas de VLT (Veículo Leve sobre Trilhos), trens, monotrilho e metrô. Em 2016, 60 municípios tinham obras em execução para mobilidade com recursos do PAC, e 70 tinham projetos em fase de ações preparatórias (Brasil, 2016).

Além do processo de reflexão e planejamento da mobilidade, iniciado em alguns municípios a partir da PNMU, e dos investimentos dos PACs, o surgimento do fenômeno nacional dos protestos de junho de $2013^{5}$ trouxe novos elementos para a elaboração das políticas de mobilidade no Brasil, tendo em vista que a grande bandeira da primeira fase das manifestações organizadas pelo Movimento Passe Livre em 2013 foi a revogação dos aumentos anunciados para as tarifas de transporte coletivo naquele período. Ainda que o alcance do impacto provocado pelas manifestações nas políticas de mobilidade seja complexo, especialmente pela conjugação de diferentes atores sociais envolvidos, pelas demandas variadas e pelo papel desempenhado pela mídia (formal e alternativa, incluindo as redes sociais), é possível verificar que houve respostas dos governos por meio tanto da anulação temporária do aumento de tarifas quanto pela programação de ações para a qualificação da mobilidade urbana.

Nesse sentido, ainda em 2013, foram disponibilizados pelo Governo Federal $\mathrm{R} \$ 50 \mathrm{bi}$ Ihões no chamado Pacto de Mobilidade Urbana, para estados e municípios que tivessem projetos focados em transporte coletivo municipal e metropolitano. Tal ação revelou um aspecto inusitado: muitos dos entes federados chamados a se candidatar ao repasse de recursos não estavam preparados para tal disponibilização, por não terem projetos desenvolvidos para implantar, ou seja, não haviam investido na atividade propositiva para a intervenção urbana focada em transportes públicos. Originalmente, os recursos federais do Pacto haviam sido pensados para as principais capitais estaduais e para os municípios com mais de setecentos mil habitantes, mas, com a escassez de projetos, 0 programa foi estendido para cidades médias (entre quatrocentos e setecentos mil habitantes) que haviam se organizado para elaborar projetos. Algumas cidades tinham somente propostas para ampliação de sistema viário para o tráfego geral e acabaram adaptando-as para 
inclusão de corredores de ônibus e ciclovias, de modo a cumprir as exigências do Ministério das Cidades para que as obras atendessem aos aspectos mais democráticos da mobilidade. Ainda que os dados de crescimento econômico recentes e as crises fiscal e política tenham freado diversos investimentos, o tema permanece prioritário na agenda das várias instâncias federativas, e as atividades de planejamento da mobilidade foram mantidas.

\section{Políticas de mobilidade e ampliação de infraestruturas}

Historicamente, o investimento em ampliação da infraestrutura de circulação esteve associado à ideia de progresso e desenvolvimento, tanto para eleitores quanto para os eleitos, por considerarem que o problema do atendimento das demandas por deslocamentos se relacionasse somente à ausência de elementos integradores nas cidades, deixando de lado os padrões de ocupação urbana que, por suas características, conformam territórios deficientes em integração - especialmente aqueles marcados pela segregação de usos do solo, baixas densidades e urbanização dispersa. Mais do que isso, a ampliação de redes desacompanhada de análises e ações de planejamento urbano mostra-se, por si, como indutora de padrões de crescimento que tendem a reduzir a eficiência das intervenções para a mobilidade e a reproduzir espaços desarticulados nas cidades. Como destaca Herce Vallejo (2009):

0 papel das infraestruturas como fator de desenvolvimento econômico levou a uma permanente reivindicação de ampliação de redes e de aumento de sua complexidade. 0 paradoxo está no fato de que a ampliação indiscriminada de redes de infraestruturas se traduz em mais dispersão da cidade, o que gera, entre outras coisas, um modelo de mobilidade insustentável, de alto consumo de energia e de crescente internalização de custos para amplas camadas da população. (p. 17; tradução nossa)

Assim, o recente destaque ao tema da mobilidade urbana na pauta pública brasileira coloca um desafio para as políticas relacionadas à circulação sobre como a leitura da estrutura urbana e produtiva de municípios e regiões metropolitanas pode sistematizar e encaminhar o tratamento dos assuntos pertinentes ao planejamento dos deslocamentos da população tendo em vista a urgência com que se colocam o assunto na agenda de governos e os efeitos das intervenções nas dinâmicas urbanas locais. A promulgação da Lei da Política Nacional de Mobilidade Urbana, os protestos de junho de 2013 e os vultosos investimentos anunciados por diversas esferas de governo impõem, assim, uma necessária revisão crítica do modo de planejar a mobilidade urbana no Brasil para a superação - do ponto de vista urbanístico, ambiental e socioespacial - de modelos insustentáveis de desenvolvimento compreendidos como a expressão do poder do capital, notadamente transnacional, ao ocupar o solo e determinar - mesmo com contradições - fluxos de circulação de bens, serviços e pessoas.

Ainda que os esforços para a implantação de novas infraestruturas sejam de fato necessários ao atendimento dos fluxos existentes nas cidades brasileiras (condicionados pelos padrões históricos de desenvolvimento que as configuraram), o desafio que se coloca no 
momento para o planejamento da mobilidade é a reflexão sobre o necessário gerenciamento de demanda por transportes, tendo em vista a relação do capital com a expansão urbana. Ao mesmo tempo que a ampliação de redes de transporte permite 0 atendimento adequado de demandas existentes, as novas possibilidades de deslocamento diferenciam porções do território e resultam em espraiamento regional se não forem acompanhadas por ações de controle espacial afeitas ao planejamento urbano.

Gerenciar a demanda por transportes objetiva, além da otimização do uso das infraestruturas implantadas, evitar processos insustentáveis de expansão da ocupação urbana possibilitada por novos sistemas de transporte que, devido às novas dinâmicas que viabilizam, rapidamente terão suas capacidades esgotadas e exigirão novos ciclos de intervenção e investimentos que endividarão ainda mais estados e municípios. Isso implica, necessariamente, a aproximação entre as políticas de mobilidade e as de uso e ocupação do solo no planejamento municipal, com ações que tratem da distribuição da oferta de residências, empregos, unidades educacionais e serviços pela cidade - tendo em vista que é o acesso a esses interesses que motiva a maior parte dos deslocamentos produzidos no meio urbano. Aqui reside a tensão - ou contradição - do processo, pois, afinal, o modelo de acumulação é o que define a alocação de pessoas e atividades econômicas no território (gerando os desejos por viagem), em contraste às ações de planejamento que procuram direcionar as atividades urbanas por meio de planos que implicam constrangimentos ao próprio modelo atual de reprodução desse capital, seus movimentos e suas formas espaciais.

\section{A interface entre as políticas de mobilidade e as de desenvolvimento urbano}

0 gerenciamento da demanda por transporte focado no planejamento urbano, apesar das limitações indicadas acima, inclui ações para tentar garantir que o crescimento das cidades reverta padrões insustentáveis de desenvolvimento urbano muito além da expansão residencial periférica descontrolada que torna os deslocamentos diários da população cada vez mais extensos com consequentes custos humanos, energéticos e ambientais. Destacam-se, nesse sentido, temas como a segregação socioespacial (localização de diferentes classes sociais em regiões distintas e fisicamente separadas na cidade), parâmetros urbanísticos (densidades, mistura de usos, padrão de ocupação de lotes e tipologias construtivas) e desenho urbano (destinação e projeto do sistema de circulação, distribuição de equipamentos públicos).

A segregação socioespacial que caracteriza a ocupação da maioria dos municípios brasileiros é relevante não somente pela iniquidade social que representa, mas também por ser altamente nociva ao desempenho dos sistemas de circulação. De um lado, verifica-se que, nos locais com alta concentração de renda, há tendência a uma divisão modal com predomínio de viagens por modo individual motorizado, 0 que dificulta a implantação de sistemas coletivos eficientes. De outro lado, as oportunidades de trabalho e estudo tendem a se localizar onde há maior renda, já que empresários querem seus negócios próximos às suas residências e comerciantes abrem lojas próximas ao seu público-alvo, fazendo que os empregos 
se distanciem das concentrações de população de baixa renda. Periferizados e sem atividades econômicas próximas de suas residências, resta a esses cidadãos realizarem diariamente longos deslocamentos pendulares, como se sabe.

Nesse sentido, vale destacar que a implantação de novas infraestruturas para a mobilidade traz em si potencial de agravamento da segregação socioespacial existente se acompanhada de valorização imobiliária exacerbada, motivada pela ampliação da acessibilidade de porções privilegiadas da cidade, levando à expulsão de populações pela elitização resultante do processo de aumento da atratividade local. Além disso, podem surgir guetos de baixa renda se as novas estruturas de circulação desvalorizarem seus trajetos por representarem impacto negativo na paisagem (por suas características físicas ou por criarem barreiras urbanas) ou se a expansão da rede tornar acessivveis áreas inadequadas à urbanização que podem ser ocupadas irregularmente.

As administrações municipais precisam estar atentas a esses processos, e existem ferramentas para fomentar a inclusão social e a interconexão de classes de renda na cidade no enfrentamento desses padrões insustentáveis, como estabelecimento de zonas de interesse social e unidades habitacionais para projetos de aluguel social no entorno de novos pontos de acesso à rede de transportes, aumento de potencial construtivo condicionado à diversificação de tipologias das unidades de um empreendimento (número de cômodos, dimensões e padrões de acabamento), limitação e não exigência de vagas de estacionamento, entre outros. Entretanto, tais ações significariam restrições às dinâmicas e ao poder do capital no capitalismo contemporâneo, levando a tensões no enfrentamento desses padrões na atividade de planejamento urbano.

Outro tema relativo ao desenvolvimento urbano diretamente relacionado à melhoria da mobilidade e ao gerenciamento de demanda são as iniciativas para a criação de cidades compactas (densas e de uso misto), nas quais os modos não motorizados de deslocamento (a pé ou de bicicleta, que exigem pouca infraestrutura e têm pequeno impacto ambiental) podem atender a grande parte das necessidades cotidianas de deslocamento dos habitantes da cidade. Para tal, as características físicas da cidade compacta incluem um desenho urbano atento às necessidades de segurança e conforto dos transportes ativos, no qual se destacam acessibilidade universal, padronização de calçadas e travessias, Zonas $30,{ }^{6}$ traffic calming $^{7}$ Ruas Completas, ${ }^{8}$ arborização para sombreamento, fachadas ativas, ${ }^{9}$ alargamento de passeios por meio de recuos frontais cobertos sob andares superiores construídos sobre pilotis e criação de caminhos pelo miolo das quadras acessíveis por passagens livres para pedestres no térreo de edifícios.

Devido à maior densidade de habitantes e oportunidades de trabalho e estudo, cidades compactas levam também ao melhor desempenho das redes de transporte coletivo, pois distribuem mais adequadamente, no espaço, as origens e os destinos de viagem, permitindo maiores frequências dos serviços (diminuição do tempo de espera dos usuários) com menos veículos devido a menores tempos de ciclo (menores distâncias dos percursos). Aumenta-se, assim, o índice de renovação de passageiros no transporte coletivo (subida e descida de usuários nas paradas entre as pontas de linhas) ao melhorar o chamado Índice de Passageiros 
por Quilômetro (IPk), sem aumentar a lotação dos veículos, o que reduz os custos do sistema. Além disso, a promoção de usos mistos do solo pode ainda dinamizar e fortalecer subcentros regionais que aumentam a atração de viagens fora de áreas já saturadas e mais próximas aos locais de moradia da população, além de promover um uso mais equilibrado do sistema viário pelos automóveis particulares. São, assim, potencialidades importantes que o planejamento e as políticas públicas podem promover, enfrentando, contudo - por vezes -, interesses dos empreendimentos econômicos.

0 fomento ao uso misto do solo ameniza, assim, as grandes diferenças de carregamento do sistema de circulação por sentido de tráfego nos horários de pico (pendularidade), o que evita a necessidade de ampliações de capacidades para suportar os fluxos com destino aos atuais polos concentradores de atração de viagens, aumentando dessa forma a probabilidade de acesso a empregos e serviços a curtas distâncias das residências. Para estimular o uso misto do solo, os municípios podem incluir, em seus códigos municipais de obras e de tributos, parâmetros específicos quanto a características edilícias, como estímulos e exigência de área mínima destinada para comércio no térreo de edifícios e equilíbrio na destinação de áreas resultantes da utilização de potencial construtivo adicional, além de incentivos fiscais e administrativos para a diversificação de atividades em bairros desequilibrados quanto ao uso do solo: tanto polos de emprego centrais com poucas habitações quanto periferias predominantemente residenciais.

Entretanto, ainda que com potencial para dinamização da atividade produtiva, a alteração dos padrões de desenho urbano das cidades representa novamente ponto de tensão com as atuais práticas de ocupação dos espaços definidas pelo modelo de produção, uma vez que pode impor constrangimentos à livre iniciativa do mercado na determinação de suas iniciativas comerciais.

É necessário destacar que há, ainda, iniciativas complementares de gerenciamento de demanda focadas no desestímulo ao transporte individual, como restrição e cobrança de uso de veículos particulares ou em ações de reorganização operacional dos fluxos urbanos por meio da racionalização do uso da infraestrutura, como flexibilização de horários de trabalho e soluções alternativas de estacionamento, ${ }^{10}$ ainda que aplicáveis somente a um grupo seleto de trabalhadores qualificados. Entretanto, ainda que possam desempenhar papeis importantes e impliquem conflitos com setores econômicos, são medidas baseadas em programas de gestão e operação do sistema viário, cujo amplo escopo vai além do recorte da discussão aqui apresentada.

\section{A conjugação das políticas de desenvolvimento urbano e de mobilidade}

Estudos detalhados sobre densidade (populacional e de empregos), localização de atividades no território e a ênfase na relação entre a infraestrutura de transporte e a organização do espaço intraurbano têm se mostrado como componentes técnicos fundamentais nos processos de tomada de decisão das políticas de mobilidade em diversos países, descritos por autores como Cervero (1998, 2001), Cervero, 
Ferrell e Murphy (2002), Goldman e Gorham (2006), Herce Vallejo (2009), Gehl (2013), Suzuki, Cervero e luchi (2013) e conceitos como "Crescimento Inteligente", "City Fix", entre outros.

A alternativa a esse processo [expansão permanente de infraestruturas e de áreas ocupadas] depende da compreensão de que somente com a concentração urbana e com maior densidade de ocupação do solo pode-se alcançar um novo modelo de mobilidade que atenda às necessidades de todos os cidadãos, de acordo com formas de deslocamento mais baratas e saudáveis. (Herce Vallejo, 2009, p. 17; tradução nossa)

Tais abordagens destacam instrumentos e metodologias específicas na definição das políticas de promoção da mobilidade, o que inclui análises de contexto urbano (concentração ou dispersão de população, padrões espaciais de distribuição de renda, empregos, matrículas); evolução histórica da mancha urbana e seus indutores; estruturação do sistema viário, redes de transporte coletivo; redes de transporte cicloviário; infraestruturas para pedestres; mercado imobiliário; localização de empreendimentos; e o papel dos nós de transporte. Esses instrumentos e metodologias, formulados nos países de capitalismo avançado como novas formas de melhoria do desempenho de cidades que competem por investimentos e concentração de poder econômico, começam a influenciar as abordagens da mobilidade no Brasil e de outros países em diferentes extensões, ainda que representem diversos conflitos diante das mudanças de paradigma que representam, afetando, além do mais, interesses constituídos.
Além disso, para que o transporte seja o condicionante de um desenvolvimento urbano mais adequado à mobilidade, os estudos internacionais têm destacado como necessárias ações que coloquem os modos coletivos e não motorizados de deslocamento (com suas respectivas capacidades e peculiaridades de utilização) como medida básica na definição de parâmetros urbanísticos de ocupação dos espaços da cidade. 0 chamado Transit Oriented Development - TOD (Desenvolvimento Orientado pelo Transporte Público) é, por exemplo, uma metodologia associada à promoção de crescimento urbano "inteligente", por meio do adensamento de atividades junto a nós de transporte coletivo, de modo a evitar o espraiamento da mancha urbana das cidades e a diminuir a dependência de automóveis nos deslocamentos de seus habitantes. 0 princípio fundamental do TOD é criar, no entorno dos pontos de acesso às redes de infraestrutura, ambientes propícios à caminhada e às bicicletas, e o próprio perímetro de cada projeto de TOD relaciona-se com as distâncias que podem ser percorridas por pedestres ou por ciclistas a partir do nó de transporte que ancora o desenvolvimento de uma comunidade equilibrada quanto à mescla de usos residenciais e não residenciais (Cervero, Ferrell e Murphy, 2002).

Apesar de seu potencial para o atendimento aos preceitos da PNMU, ainda não há exemplos de TOD implantados no Brasil, exceto o projeto iniciado em $2015^{11}$ para elaboração de proposta de TOD no município de Queimados, na Região Metropolitana do Rio de Janeiro, ancorado por desenvolvimento urbano junto à estação de trens metropolitanos da cidade (SuperVia), ainda sem resultados divulgados. Vale destacar, ainda, que o Plano 
Diretor Estratégico do Município de São Paulo de 2014 deu passo inicial de adoção dos princípios do TOD, ao definir os chamados "Eixos de Estruturação da Transformação Urbana" nas áreas de influência do sistema estrutural de transporte coletivo de média e alta capacidade, com estabelecimento de parâmetros urbanísticos diferenciados para a intensificação do uso do solo, objetivando o incentivo ao uso de formas mais sustentáveis de deslocamentos. Entretanto, não há vinculação direta da alteração de coeficientes de aproveitamento, por exemplo, a projetos de desenho urbano e intervenções específicas - especialmente as relativas à microacessibilidade e implantação de equipamentos públicos e outras infraestruturas urbanas que viabilizem urbanisticamente 0 adensamento -, o que indica o estágio ainda inicial do tema.

\section{Mobilidade urbana em escala regional}

Além das considerações acerca da dimensão urbana da mobilidade, mostra-se fundamental em determinados contextos a inclusão de escalas regionais na análise dos deslocamentos urbanos, tanto do ponto de vista metropolitano - fenômeno vastamente encontrado no território nacional - quanto em escala regional ampliada, caso da Macrometrópole Paulista, como componentes essenciais do quadro de referência para o planejamento da mobilidade.

Inicialmente, é importante destacar a necessária superação da ideia de políticas metropolitanas como aquelas relativas somente a um conjunto de municípios reunidos por força de lei estadual em uma unidade regional configurada por intensas relações intermunicipais. Tendo em vista que as dinâmicas do território metropolitano contemporâneo - expressão do estágio atual do capitalismo - subverteram a forma urbana tradicional linear, não é mais aplicável o antigo esquema de centros densos, áreas intermediárias e periféricas nem a ideia de justaposição física e funcional entre núcleos urbanos (Meyer, 2004). Assim, o tratamento das dinâmicas urbanas que extrapolam os limites municipais e criam um conjunto de espaços urbanos relacionados por complexas conexões espaciais e funcionais exige do planejamento da mobilidade metropolitana a revisão da definição de toda a Região Metropolitana como unidade para políticas públicas.

Nesse sentido, Borja e Castells (1997) definiram o conceito de Cidade Metropolitana para designar fenômenos urbanos encontrados nas metrópoles contemporâneas, superando o modelo clássico da "conurbação", de modo a caracterizar de forma mais precisa o contexto complexo em que políticas metropolitanas, incluindo as de mobilidade, devem ser planejadas. Meyer (2004) descreve assim o conceito:

A Cidade Metropolitana é um espaço urbanizado de forma contínua no qual se organiza uma realidade econômica, social, cultural e funcional de ampla abrangência, cujo traço mais evidente é a dissipação da urbanização em todo o território. [...] Essa dissipação não resulta em um território coeso do ponto de vista urbano, pois a dispersão e a descontinuidade correspondem a formas internas de organização do tecido e das funções urbanas. (p. 79) 
0 recorte territorial proposto pelo conceito de Cidade Metropolitana indica o contexto de análise em que instituições públicas podem considerar o planejamento de ações ligadas à mobilidade urbana. Isso por levar em conta que a dissipação da urbanização nas regiões metropolitanas implica um conjunto de atividades organizadas em redes com diferentes níveis de estruturação, de modo que é a articulação de setores urbanos por meio de pontos nodais 0 que demanda atenção nas proposições com foco em mobilidade, tendo em vista condicionantes específicos.

A compreensão das "Cidades Metropolitanas" como espaço para políticas públicas específicas é pertinente a diversas áreas de atuação pública, pois o desenho de projetos governamentais para meio ambiente e regulação de uso do solo, ou os investimentos em saneamento, drenagem, habitação, sistema viário e transporte público apresentam, em grandes manchas urbanas, um arcabouço jurídico, político e técnico específico, relacionado ao funcionamento do organismo metropolitano e à divisão administrativa federativa. Nesse sentido, um conjunto de "condicionantes metropolitanos para políticas públicas" deve ser destacado: a escala dos problemas (conjugação de questões locais, regionais e globais; superação de ações monossetoriais), a necessidade de articulação institucional e intergovernamental (cooperação federativa, negociação, jogo político, peso político e econômico do município-sede) e a complexidade de relações urbanas e regionais (físicas, funcionais, econômicas e sociais). (Cruz, 2012, pp. 57-58)

0 desempenho dessas regiões metropolitanas e a qualidade de vida nelas dependem, assim, da eficiência com que o território e suas infraestruturas promovem o relacionamento entre os sistemas de circulação e a localização das atividades. Dessa forma, repousam nas políticas de mobilidade (compreendidas como conjugação de serviços de transporte, infraestruturas, políticas de uso do solo e de qualificação do meio urbano) os subsídios para reestruturação das cidades e do conjunto da metrópole, tanto por seu papel de atendimento às necessidades de circulação quanto pelas orientações que podem oferecer para o planejamento do desenvolvimento metropolitano de forma confluente ou contrastante às dinâmicas do capitalismo contemporâneo.

A hipótese de que as grandes infraestruturas urbanas, com ênfase nos sistemas de transporte de massa e mobilidade, ganharam a prerrogativa de funcionar como elementos "agregadores" dos territórios metropolitanos vem ganhando força. Sua principal função é organizar os sistemas e subsistemas urbanos. A estruturação metropolitana depende diretamente da sua capacidade de acompanhar a dinâmica de localização das atividades e garantir as continuidades ameaçadas pela fragmentação, organizando os fluxos e evitando a dispersão funcional. (Meyer, Grostein e Biderman, 2004, p. 164)

É importante destacar, ainda, que a recente lei n. 13.089, de 12 de janeiro de 2015, que instituiu o Estatuto da Metrópole, prevê a elaboração do Plano de Desenvolvimento Urbano Integrado (PDUI) para as regiões metropolitanas brasileiras. Nestas, a lei impulsiona a incorporação das diretrizes para as funções públicas de interesse comum, incluindo projetos estratégicos e ações prioritárias para investimentos (abrangendo ações para a mobilidade urbana), integradas ao macrozoneamento, 
à articulação dos municípios no parcelamento, uso e ocupação no solo urbano e à articulação intersetorial das políticas públicas afetas à região. Não existem, no momento, exemplos de PDUI já elaborados à luz do Estatuto da Metrópole, mas alguns já estão em andamento (como os planos para as regiões metropolitanas do Rio de Janeiro e de São Paulo) e brevemente poderão ser analisados acerca do tratamento dado à mobilidade metropolitana como estruturadora do território de forma integrada ao planejamento do uso do solo, tendo em vista as dinâmicas do modelo econômico contemporâneo que ancora nas metrópoles seus espaços de produção.

Especificamente nas análises de mobilidade urbana na Região Metropolitana de São Paulo, tem se mostrado pertinente, além da escala metropolitana, a inclusão da verificação das relações urbanas que ultrapassam os limites da metrópole, tendo em vista o conjunto de regiões metropolitanas e aglomerações urbanas que constituem a chamada Macrometrópole Paulista. ${ }^{12}$ Esta se configura como organismo territorial cuja existência tem ligação direta com as possibilidades e dificuldades de deslocamento de pessoas e bens. Como destaca Reis (2006, p. 91):

Uma parcela significativa da população passa a ter a vida organizada em escala regional. As cidades deixam de ser as sedes da vida cotidiana, para se transformarem em polos de um sistema articulado em escala mais ampla, regional, no qual se desenvolve a vida cotidiana.

A Macrometrópole Paulista é um território formado em um raio de aproximadamente 200 quilômetros da capital, constituído pelas regiões metropolitanas de São Paulo,
Campinas, Vale do Paraíba e Litoral Norte, Baixada Santista e Sorocaba, e as regiões de Piracicaba, Jundiaí e Bragança Paulista, com 174 municípios. A Macrometrópole, que conta com mais de 33 milhões de habitantes em 53,4 mil quilômetros quadrados e contribui com $27,6 \%$ do PIB brasileiro (Emplasa, 2012), caracteriza-se pela dispersão da urbanização no território e pela localização de atividades articuladas pelo sistema rodoviário regional polarizadas pela RMSP como centro financeiro e administrativo. Destacam-se, na região, a intensa dinâmica funcional entre seus municípios e a multiplicidade de funções desempenhadas localmente, que incluem núcleos de pesquisa científica e tecnológica, polos educacionais, áreas de proteção ambiental, mananciais, centros logísticos, indústrias, refinarias, portos, aeroportos, redes de oleodutos e gasodutos. ${ }^{13}$

A articulação física dos espaços da macrometrópole pelo sistema viário regional poderá ser incrementada com as perspectivas de implantação tanto do Trem de Alta Velocidade (entre Campinas e Rio de Janeiro, com paradas no aeroporto de Viracopos, centro de São Paulo, aeroporto de Cumbica e São José dos Campos) quanto da rede de trens regionais planejada pelo Governo do Estado de São Paulo (ramais Americana-Santos e Sorocaba-Pindamonhangaba, com 432 km de linhas interligando 14 cidades à capital e aos aeroportos de Campinas e Guarulhos). Quanto a esta, far-se-á por meio de Parceria Público Privada (PPP), estimada em $\mathrm{R} \$ 20$ bilhões, trazendo novo elemento (ainda sem qualquer prazo para implantação) sobre a conjugação de escalas na análise da mobilidade urbana. As paradas dessas linhas regionais de transporte de passageiros sobre trilhos surgirão como equipamentos que proporcionarão 
acessibilidade privilegiada a seus contextos locais e que demandarão análise sobre o uso do solo tanto em seu entorno imediato quanto na totalidade de seus municípios, os quais se tornarão alternativas locacionais ainda mais atraentes e possivelmente reforçarão a dispersão da urbanização na macrometrópole.

\section{Considerações finais}

A conjugação entre uso e ocupação do solo, mobilidade urbana e modelo de acumulação (flexível) capitalista não é tarefa simples, uma vez que mobiliza três vetores per se complexos. Deve, contudo, ser intentada sob pena de não se compreender a relação entre essas três variáveis, tornando discussões, projetos e leis falhos ou estéreis ao não os analisar como um todo orgânico, embora eivado de conflitos e contradições.

Deve-se, portanto, ao articular essas dimensões, observar seus alcances e limites. No caso das peças legais, tais como os Planos de Mobilidade Urbana, exigidos pela lei 12.587, e das metrópoles que terão Planos de Desenvolvimento Urbano Integrado à luz da lei 13.089, essa dicotomia não é compreendida em geral, como uma tese, e sim em seus contornos específicos nos lugares onde são, ou não, implementados.

Assim, no contexto da Política Nacional de Mobilidade Urbana, torna-se necessária a investigação acerca de perspectivas e diretrizes para a superação, quanto ao planejamento da mobilidade, do aspecto setorial do planejamento de transportes. Para tal, mostra-se relevante sistematizar e avaliar criticamente a intrínseca ligação entre a qualificação dos sistemas de circulação e os condicionantes urbanísticos dos deslocamentos urbanos, especialmente os padrões de uso do solo e de localização das atividades nas cidades no contexto do capitalismo flexível.

Entre os Planos de Mobilidade já produzidos no País, publicados antes e depois da PNMU, a relação entre mobilidade e uso do solo vem sendo tratada com distintos alcances quanto à conjugação de escalas de análise urbana para a definição de suas proposições e quanto ao tratamento do tema do uso do solo em seus cenários de planejamento. Ainda é incipiente o destaque às relações entre urbanismo e mobilidade - assim como, em meio a ambos, o papel do modo de acumulação capitalista contemporâneo, reitere-se -, especialmente a correlação entre densidades (de residentes e empregos) e oferta de comércio e serviços que configuram meios urbanos mais equilibrados, de modo que as proposições resultantes desses planos raramente incluem ações que conformem cenários de desenvolvimento urbano mais propícios à mobilidade.

Mesmo o diálogo dos Planos de Mobilidade com os Planos Diretores Municipais ainda se mostra limitado, sem avaliação crítica das disposições presentes nas leis municipais de ordenamento da ocupação do território à luz da mobilidade e com poucas contribuições relevantes para os processos de revisão regulares dos planos diretores. Isso revela como potenciais constrangimentos à atividade produtiva relacionados às questões de mobilidade tensionam o planejamento urbano e demarcam um campo de ação estatal com limitados avanços. Deve-se notar que, a depender da correlação de forças existentes em nível local, regional e mesmo nacional, os interesses - normalmente 
de curto prazo - dos empreendimentos econômicos, sobretudo nessa fase de grande concentração oligopólica e rentista do capitalismo, podem ser relativamente congruentes à legislação de uso e ocupação do solo e de mobilidade, ou, ao contrário, profundamente antagônicos. Mais ainda, o capital pode se sobrepor à legislação, seja no sentido de ameaçar não investir ou desinvestir, seja atuando como ator político hegemônico por meio de partidos políticos, aparatos midiáticos, associações industriais e empresariais e outros.

Vale ressaltar, outrossim, que a exigência dos Planos de Mobilidade pela lei 12.587 em um prazo exíguo impôs urgência ao desenvolvimento desses documentos pelas prefeituras brasileiras, elevando a velocidade de elaboração desses planos de forma muitas vezes incompatível com o tempo necessário à acuidade dos temas tratados. Isso resultou, em muitos casos, em planos mais orientados a cumprir exigências formais do que, de fato, a configurar oportunidades amplas de análise e proposição afeitas à atividade de planejamento. Não se trata de apontar que três anos são insuficientes para tal trabalho, mas que o processo completo exige tempo e esforços de preparação das administrações municipais, especialmente a disponibilização de corpo técnico habilitado ao desenvolvimento do plano, tão escasso em grande parte das prefeituras brasileiras. Iniciando-se pela compreensão e definição do escopo obrigatório dos planos, seguindo pela busca por recursos, levantamento de informações, eventuais licitações para contratação de consultorias e, finalmente, aprovação dos projetos de lei de instituição dos planos - sem contar as incertezas e revezes dos procedimentos administrativos -, tem-se, ainda que parcialmente, uma explicação para que a maioria dos municípios não tenha cumprido o prazo original ou tenha acelerado a elaboração dos estudos técnicos que embasaram seus planos. Por outro lado, a falta de priorização do tema pelas prefeituras brasileiras relaciona-se, por hipótese, às restrições que as potenciais discussões sobre mobilidade urbana poderiam representar às dinâmicas do capital, que se impõem para além de qualquer planejamento, como o afirmamos.

Essa condição limitada da atividade de reflexão urbanística dos municípios deve, todavia, ser avaliada sob perspectiva histórica, como primeiro passo para a constituição de um texto básico que propicia, na maior parte das prefeituras brasileiras, processo amplo de planejamento da mobilidade vis-à-vis, o uso e a ocupação do solo, ou seja, produz pela primeira vez nos municípios - de extensão, população e atividade econômica distintas - discussão estruturada em documentos sobre o tema, ainda que dentro dos limites dados, em grande medida, pelos empreendimentos econômicos.

Por fim, deve-se ressaltar o papel do tensionamento que, em larga medida, os códigos legais podem produzir perante os capitais privados, no sentido de equilibrar - mesmo que, por vezes, em bases tênues - os interesses dos empreendimentos econômicos, de monta distinta, com os dos trabalhadores, em suas diversas tipologias: trabalho intelectual e braçal, de qualificações distintas. 0 capitalismo pode ser, assim, mais equilibrado e sustentável se o poder público, apoiado por grupos organizados de cidadãos, de fato possuir instrumentos 
legais, políticos e operacionais para estabelecer a dimensão pública das cidades e, sobretudo, a proteção aos grupos sociais mais vulneráveis, notadamente nessa etapa do capitalismo flexível e precarizador das relações sociais e de trabalho.

[I] http://orcid.org/0000-0003-1410-9157

Universidade de São Paulo, Faculdade de Arquitetura e Urbanismo, Programa de Pós-Graduação em Arquitetura e Urbanismo. São Paulo, SP/Brasil.

mauriciofeijo@usp.br

[II] https://orcid.org/0000-0003-4339-4786

Fundação Getúlio Vargas, Escola de Administração Pública, Departamento de Gestão Pública. Pontifícia Universidade Católica de São Paulo, Faculdade de Ciências Sociais, Departamento de Política. São Paulo, SP/Brasil.

franciscocpfonseca@gmail.com

\section{Notas}

(1) Utiliza-se a denominação ultraliberal, e não neoliberal, dada a radicalidade dos diagnósticos e das proposições realizadas pela corrente liberal hegemônica desde os anos 1970 e vigente nos dias de hoje. Deve-se ressaltar que, da mesma maneira que a social democracia expressava ideologicamente o modelo de acumulação fordista/keynesiano, o ultraliberalismo sintetiza a acumulação flexível. A questão urbana e, nela, das metrópoles e macrometrópoles, é fortemente moldada pelos interesses do grande capital imobiliário que, por sua vez, em larga medida está a serviço de outras frações do capital. Dessa forma, tal lógica e dinâmica do capitalismo flexibilizado, que tende a se sobrepor aos modelos de planejamento ao "impor" padrões de uso e ocupação do solo, impacta fortemente o ambiente urbano, normalmente incapaz de enfrentar o poder do dinheiro que, além do mais, financia - legal ou ilegalmente - partidos e candidatos (Fonseca, 2005).

(2) Evidentemente há exceções, com planos de transporte e mobilidade que buscaram incorporar os aspectos de desenvolvimento urbano em suas formulações, como o Pitu 2020 (Plano Integrado de Transportes Urbanos) e sua revisão no Pitu 2025, o PlanMob BH 2010 (Plano de Mobilidade Urbana de Belo Horizonte) e, mais recentemente, o Plamus 2015 (Plano de Mobilidade Urbana Sustentável da Grande Florianópolis).

(3) A lei n. 13.406, de 26/12/2016, alterou esse prazo para 6 anos, e a medida provisória 818/2018 para 7 anos, ou seja, para abril de 2019.

(4) A polêmica gerada recentemente em São Paulo quanto à implantação das ciclofaixas e ciclovias é exemplo de como a alteração das estruturas de mobilidade tem potencial explosivo. 
(5) Embora haja diversas explicações possíveis para o surgimento das chamadas "jornadas de junho", é fato que se tratou de fenômeno complexo e multifacetado. Mas um aspecto central diz respeito à mensagem que enviou às autoridades quanto à insatisfação com a mobilidade nas cidades brasileiras, ao desconforto, ao preço e à qualidade do transporte público.

(6) Perímetros com velocidade máxima de $30 \mathrm{~km} / \mathrm{h}$ para o tráfego de veículos, indicados em vias de tráfego local e com grande fluxo de pedestres (atraídos por comércio, parques, escolas ou hospitais) ou junto a áreas predominantemente residenciais. As Zonas 30 permitem a convivência entre pedestres e motoristas, compreendendo o potencial conflito que existe entre eles.

(7) Traffic Calming, ou moderação de tráfego, consiste na redução da velocidade dos veículos nas vias, independentemente de elementos de fiscalização, com desenhos viários que limitem os deslocamentos por automóvel conjugados à destinação de espaços adequados ao trânsito seguro e confortável de pedestres e ciclistas.

(8) Ruas Completas (Complete Streets) referem-se aos logradouros aptos a serem utilizados por todas as pessoas, independentemente de suas necessidades ou da forma como elas se deslocam pela cidade, ao destinar espaços seguros para o trânsito de bicicletas, proporcionar melhores condições de uso do transporte público e privado, permitir deslocamento a pé mais confortável, além de criar áreas de convivência para as pessoas. Trata-se, assim, de metodologia de desenho viário que permite a democratização da utilização do espaço público de circulação.

(9) O conceito de Fachadas Ativas refere-se à ocupação da testada dos lotes urbanos, junto aos passeios públicos, de modo a promover interação dos transeuntes com as atividades instaladas nos térreos das edificações. A importância das Fachadas Ativas para os deslocamentos não motorizados se relaciona ao fortalecimento da vida urbana nos espaços públicos, à segurança dos pedestres e à fruição da rua como local de circulação e de estar na cidade.

(10) Para a racionalização e reorganização do uso das infraestruturas, destacam-se: políticas, regulamentações e programas de estímulo a esquemas de horários alternativos de trabalhos (semanas comprimidas $4 / 40$ e 9/80); soluções alternativas de estacionamento e estacionamento compartilhado; caronas programadas (car-sharing); horários flexíveis de viagens; planejamento de viagens em tempo real por meios eletrônicos; estacionamento e transferência modal (park \& ride); car-pooling, van-pooling e serviços de transporte especial (shuttle service); teletrabalho (telecommuting); planos de mobilidade corporativa; e planos de logística de cargas urbanas.

(11) Organização da Câmara Metropolitana de Integração Governamental do Rio de Janeiro com financiamento do Banco Mundial.

(12) O advento das macrometrópoles relaciona-se diretamente à expansão das atividades produtivas (estruturas físicas, fluxos, dinâmicas), ampliando significativamente os negócios e todos os deslocamentos (cargas, pessoas), inclusive virtuais, assim como as infraestruturas que o acompanham. Tudo isso ocorre ou à margem do planejamento do poder público ou de forma fragmentada por meio de estímulos de prefeituras e elites locais.

(13) Deve-se ressaltar que, no caso específico da Macrometrópole de São Paulo, o fato de o mesmo agrupamento político estar no poder desde a década de 1980 contribuiu para a confluência de interesses entre o grande capital e o planejamento estadual - embora não inteiramente -, o que implicou conformação do último ao primeiro. 


\section{Referências}

BRASIL (Ministério do Planejamento) (2016). Empreendimentos do PAC em mobilidade urbana. Disponível em: http://www.pac.gov.br/infraestrutura-social-e-urbana/mobilidade-urbana. Acesso em: 31 jan 2016.

CERVERO, R. (1998). The transit metropolis: a global inquiry. Washington (DC), Island Press.

(2001). "Integration of urban transport and urban planning". In: FREIRE, M. e STREN, R. E. (orgs.). The challenge of urban government: policies and practices. Washington (DC), The World Bank Institute.

CERVERO, R.; FERRELL, C. e MURPHY, S. (2002). Transit-oriented development and joint development in the United States: a literature review. Washington (DC), Transportation Research Board. Disponível em: http://onlinepubs.trb.org/onlinepubs/tcrp/tcrp_rrd_52.pdf . Acesso em: 27 jul 2014.

CRUZ, M. F. (2012). Condicionantes metropolitanos para políticas públicas: análise dos transportes coletivos na Região Metropolitana de São Paulo (1999-2009). São Paulo, Hucitec.

DARDOT, P. e LAVAL, C. (2016). A nova razão do mundo - ensaio sobre a sociedade neoliberal. São Paulo, Boitempo.

EMPLASA - Empresa Paulista de Planejamento Metropolitano (2012). Macrometrópole Paulista 2012. O maior sistema urbano do Brasil. Disponível em: http://www.emplasa.sp.gov.br/emplasa/ ProjetosEstudos/Relatorios/arquivos/BrochuraMMPortuguesV2.pdf. Acesso em: 27 jul 2014.

FONSECA, F. (2005). O consenso forjado - a grande imprensa e a formação da agenda ultraliberal. São Paulo, Hucitec.

GEHL, J. (2013). Cidades para pessoas. São Paulo, Perspectiva.

GOLDMAN, T e GORHAM, R. (2006). Sustainable urban transport: four innovative directions. Technology in Society, v. 28, pp. 261-273.

GOMIDE, A. de A. (2008). Agenda governamental e o processo de políticas públicas: o projeto de lei de diretrizes da política nacional de mobilidade urbana. Brasília, Ipea.

HARVEY, D. (2004). Condição pós-moderna. São Paulo, Edições Loyola.

(2014). Cidades rebeldes: do direito à cidade à revolução urbana. São Paulo, Martins Fontes.

HERCE VALLEJO, M. (2009). Sobre la movilidad en la ciudad: propuestas para recuperar un derecho ciudadano. Barcelona, Editorial Reverté.

MEYER, R. M. P. (2004). São Paulo - Cidade Metropolitana. Tese de Doutorado. São Paulo, Universidade de São Paulo.

MEYER, R. M. P.; GROSTEIN, M. D. e BIDERMAN, C. (2004). São Paulo Metrópole. São Paulo, Editora da Universidade de São Paulo, Imprensa Oficial do Estado de São Paulo.

OFFE, C. (1984). Problemas estruturais do Estado capitalista. Rio de Janeiro, Tempo Brasileiro. 
REIS, N. G. (2006). Notas sobre urbanização dispersa e novas formas de tecido urbano. São Paulo, Via das Artes.

SUZUKI, H.; CERVERO, R. e IUCHI, K. (2013). Transforming cities with transit: transit and land-use integration for sustainable urban development. Washington (DC), World Bank.

Texto recebido em 30/maio/2017

Texto aprovado em 8/ago/2017 